\title{
Common Predictors for Explaining Youth Antisocial Behavior: A Longitudinal Studies Perspective
}

\author{
Carolyn S. Gentle-Genitty, MSW, \\ Indiana University School of Social Work \\ 902 West New York Street, ES 4162 \\ Indianapolis, Indiana 46202-5156 \\ Email: cgentleg@iupui.edu
}

Carolyn Gentle-Genitty will be corresponding author for this manuscript.

Running Title: COMMON PREDICTORS FOR EXPLAINING YOUTH ANTISOCIAL
BEHAVIOR

Key Words: Antisocial Behavior, Longitudinal Studies, Predictors, Risk, and Protective Factors

Gentle-Genitty, C. (2010). Common Predictors for Explaining Youth Antisocial Behavior: A Perspective From Ten Longitudinal Studies. Social Work in Mental Health, 8(6), 543-559. https://doi.org/10.1080/15332980902983824 


\section{Common Predictors for Explaining Youth Antisocial Behavior:}

\section{A Longitudinal Studies Perspective}

Youth antisocial behavior often consists of any behavior committed against societal norms (Walker, Colvin \& Ramsey, 1995). What foretells a youth’s engagement in antisocial behaviors is often referred to as predictors. Predictors are factors, in a child's personal characteristics or environment, which can help to predict (with some certainty) a child's future behaviors. Predictors are often expressed using the epidemiological approach of risk and protective factors. This approach originated in the field of medicine. Often used by doctors to examine the factors that put patients at risk for a particular disease, e.g., heart disease and what factors buffered or kept them at bay. For general research purposes, it is used as an organizational pattern that delineates between the bad and good factors of a social problem, often within the life domains of the individual, family, peer, school, and community (Bogenschneider, 1996).

Knowing and understanding these predictors is not the only aim. Predictors of youth antisocial behavior are but one lens from which to examine changes in a youth's behavior. However, by itself, it does nothing to ameliorate the behavior or other social problems (Laub \& Sampson, 2003). A youth’s development to adulthood is complex (Bronfenbrenner, 1979). When one understands the predictors and the need to prioritize them, then can the predictors be used to effectively respond to the current problem. Thus there are ethical and professional obligations in doing so. It is imperative for practitioners and researchers to go beyond identification, to problem solving (Bartlett, 2003). Because it is through relevance, ability for application, and impact on policy, and research that research informs practice (Chambers, 2000). 
It is through this extra step that researchers can begin to affect change and gain the tools to empower rather than attach diagnostic labels with potential to harm. For this reason this paper focuses generally on antisocial behaviors. It does not focus on the DSM diagnoses of conduct and oppositional defiant disorder for children 14-17 years of age.

The aim of the paper is to conduct a brief, yet critical evaluation of ten popular longitudinal studies to explain what factors predict youth antisocial behaviors. The paper briefly presents a discussion on the study of antisocial behavior in the last decades; review of how the behavior and factors relating to it has been studied; and findings on each of the ten longitudinal studies. It then discusses the predictors, found after pooling together common predictors from each study, followed by recommendations for future study.

History of studies on youth antisocial behavior in the last 5-6 decades

According to Howell (2003), a national focus on this 'modern disease,' (Downing, Stepney \& Jordon, 2000, p.69) of youth antisocial behavior began in the late 1980s. Catalano, Berglaund, Ryan, Lonczak, and Hawkins (1998) conjecture that concerns span earlier into the 1950s and advanced in the 1960s along with other woeful changes in divorce, single parenthood, poverty rates and even family mobility. This ushered in the need for society as a whole to reconceptualize both community and school practices to help the family raise exemplary children (Hernandez, 1993). Barton (2004) and Bernard (1992) add that the history dates back to the time of rapid industrialization where there was a surge in the nation's poor, especially youth. Society wanted to be safe from victimization (Reiss, 1986). In response to this and many other changes brought about by the moved to an industrial country, the juvenile justice system began to focus on individualized interventions tailored to safeguard the public (by ensuring supervision and 
treatment) (Howell, Krisberg, Hawkins \& Wilson, 1995; Olson, 1997). The aim was to help foster better character in youth and decrease the number of crimes and its prevalence (Catalano, et al., 1998). The movement also sparked many strategies to deal with the manifestations of youth antisocial behavior. The response to the behaviors rests in two camps, the get tough, and the go soft approaches. The get-tough approach of the late 1970s and 1980s produced many policy changes in the 1990s. The go soft approach of the 1960s is the least restrictive philosophy (Bartollas \& Miller, 2005). This philosophy espouses that society does whatever it takes to keep from institutionalizing juveniles. To date the get tough approaches are used more prevalently (Howell, 2003; Reid \& Eddy, 1997).

\section{How has antisocial behavior been studied?}

In a developing field there are always opportunities to enhance methodological processes. This is especially true when working with young people. The need for methodology enhancement comes from the shortcomings of current methodologies. The field of antisocial behavior has used retrospective, cross-sectional, and experimental study designs to understand development, engagement, and desistance in behaviors (Loeber \& Farrington, 2001; Stoff, Breiling \& Maser, 1997). These studies utilized psychometric tests, self-reports, police records, FBI reports of arrests and incidents, the combination of standardized instruments, parent/teacher reports and agency statistics to enhance the knowledge of engagement in antisocial behavior (Howell, et al., 1995; Loeber, 1990; Loeber \& Farrington, 2001; Stoff, Breiling \& Maser, 1997). In addition, others have used personal histories and narratives, through the person-centered and variable-centered approaches to compliment the measurement of impact and engagement in antisocial behaviors (Laub \& Sampson, 2003). Many of these studies have been quantitative in 
nature, mainly using a variable-based approach. The difficulty with this approach is it categorizes the behavior that leads to labeling instead of helping to understand or respond to social problem.

Another popular method of studying the impact of antisocial behavior is the longitudinal prospective research design (Huizinga, Loeber, Thornberry \& Cothern, 2000; Stoff, et al., 1997). Huizinga, Loeber and Thornberry (1994) define a longitudinal study as one "in which repeated observations are made on the subjects over time; which differs from a cross-sectional study design in which subjects are observed at one point in time” (p.27). Longitudinal studies add more credence to shape the results in patterns of understanding over time (Farrington \& Coid, 2003; Huizinga, et al., 1994). These studies help to ascertain possible causation over the lifecourse of the subjects reviewed, rather than isolating specific aspects for study (Rutter, Giller \& Hagell, 1998). However, few longitudinal studies exist that have explicitly explored antisocial behavior engagement (Farrington \& Coid, 2003). This methodology has its drawbacks in that ascertaining results takes time. By the time results are available, the findings seem outdated (Laub \& Sampson, 2003).

Researchers continue to explore causal links to antisocial behavior (Rutter, Giller \& Hagell, 1998). Since the start of this phenomenon (antisocial behavior) centuries ago, researchers have wanted to know the causes, impact, and predictors of youth antisocial behavior (Catalano, et al., 1998). To date strong and consistent links have been identified (Hawkins, 1996; Howell, 2003; Loeber, 1996; Loeber \& Farrington, 1998; Office of the Surgeon General, 2001). In the last two decades, researchers began to realize longitudinal studies could most 
effectively, identify common predictors of antisocial behaviors over the life-course, rather than cross sectional (of one point in time) studies.

\section{Selection strategy for longitudinal studies}

Studies included in this review were identified from a compilation of text, electronic sources, and references of major sources. The goal was to ascertain the most major longitudinal studies discussed in the literature on youth antisocial behaviors. Then create a list of common predictors, among these studies, on explaining youth antisocial behavior. Studies were included that met the criteria of being longitudinal and contained a large sample. Of the studies included, the smallest sample was 206 participants (the Oregon study). In addition, studies must have examined aspects of youth antisocial behavior prospectively or attempted to draw out possible risk and protective factors from the five life domains. The result yielded ten longitudinal studies. These studies and reviews formed a practical guide with regard to similar risk and protective factors for youth antisocial behavior. Following the review of each study predictors, factors that were common in each study were pooled together. Factors expressed differently but referred to a general category, were be lumped together to create the list of common predictors.

\section{Description of Longitudinal Studies}

The ten longitudinal studies varied in program, assessment, location, and measurement. However, thy all identified, from their findings common predictors to explaining youth antisocial behavior. An attempt to briefly explore each study follows.

General description of studies

The Kauai study was a longitudinal birth cohort (698) study conducted in the Hawaiian Islands of Kauai. This study monitored the impact of biological and psychosocial risk factors, 
stressful events, and protective factors on the development of men and women born on the island in 1955. The researchers assessed development from pre/perinatal period to age forty. Semistructured interviews with nurses, doctors, family, and other professionals, charted development (Werner \& Smith, 2001). Findings: This study found that the assessment of the study population at ten years showed that $25 \%$ needed mental health services. 80 percent of the participants displayed conduct disorders, and overt antisocial behavior by the age of 18. 20 percent were diagnosed with adjustment problems, and socio-pathic personalities. Those youths that had cumulative biological predisposition, care giving deficits during the first decade, and lived in chronic poverty, were most at risk antisocial behavior.

The Cambridge Study was a ten-year longitudinal study. It followed a cohort (411) of high schools students from 8 years old to age 46 . The study aimed at collecting data on the development of juvenile delinquency, and to see, in the event, which items or which combinations of items, would prove to be the clearest determinants of future delinquency” (West, 1969, p.2). Data was collected from psychological tests, teacher reports, interviews, questionnaires and home visits by social workers (West, 1969; West \& Farrington, 1973; West, Farrington, Gundry, Knight, \& Osborn, 1977). Findings: The best single predictor of delinquency was the rating of troublesomeness assessed by student's classmates at age 10 and by their teachers at age 8 and 10. Ninety-two of the sample boys were categorized as troublesome with 41 becoming delinquent and 25 juvenile re-offenders. In addition 5 background factors also impacted prediction criminal parents, low family income, large family size, poor parental behavior, and low intelligence. Early background factors were very important influences upon the likelihood of a boy engaging in antisocial behaviors. 
The Pittsburgh study is a longitudinal quantitative prospective initiated in 1994. The study consisted of three samples of $500(\mathrm{~N}=1,517)$ ten year old boys initially studied in the $1^{\text {st }}$, $4^{\text {th }}$ and $7^{\text {th }}$ grades. Data for the study was gathered using private, face-to-face interviews while their caregiver and teacher completed questionnaires. Mothers completed the Child Behavior Checklist. Teachers completed the Child Behavior Checklist and the Teacher Report Form (Farrington, Loeber, Stouthamer-Loeber, Van Kammen \& Schmidt, 1996; Loeber, et al., Caspi, 1998). Findings: There were high levels of involvement in serious delinquency among the three samples. There were no differences between African American and Caucasian boys at 6 years old. The differences gradually increased with prevalence of delinquency at 16 years (27\% African American boys versus 19\% Caucasian boys). As prevalence of antisocial behavior increased so did the average frequency, especially for African American boys versus Caucasian. In addition, the onset of offending for boys' involved in serious delinquency increased by age 15 (51\% African American and 28\% Caucasian boys).

The Dunedin Multidisciplinary Health and Development Study was a prospective longitudinal investigation of a birth cohort of both boys and girls 3 years old to age 21 . The study was conducted to predict whether serious antisocial behavior at age 11 could be effectively predicted as early as the preschool years. It then studied those same predictors to see if they were predictors of delinquency in adolescence at age 15. Data for the study was collected using standardized testing instruments, parent, teacher, self-report, psychiatric interviews, and police data. To guard against bias the data was collected at multiple time points. Extensive psychological, social and physical data was collected systematically at ages 3, 5, 7, 9, 13, and 15 (White, et al., 1990). Findings: There are differences but males and females are likely to differ 
in their antisocial behavior between ages 14 and 15.1 in every 100 females in a birth cohort was on the life-course-persistent path. When on that path the sexes shared similar risk factors of poor discipline, family adversity, cognitive deficit, uncontrolled temperament, hyperactivity, and rejection by peers. Almost all females who engaged in antisocial behaviors best fit the adolescence-limited type ratio of 1 to 5 (female to male).

The Chicago Youth Development Study was a longitudinal study initiated in 1991 evaluated the development of delinquency among African American and Latino male adolescents living in the inner city. The sample for the study were boys recruited from $5^{\text {th }} \& 6^{\text {th }}$ grades from 17 public schools $\mathrm{N}=341$ at $13 \& 17$ years old. Data was collected using multilevel, multiwave assessment measures such as screening through the Child Behavior Checklist. Thereafter, $75 \%$ of eligible participants were asked to complete interviews. Comparisons were then made for those completing only one wave and those continuing to participate in subsequent waves (Sheidow, et al., 2001). Findings: Family functioning affects violence exposure. Violence exposure is linked to poor family functioning but only in communities that are very impoverished and that have social networks that are providing support and concern. As a result in communities plagued with social ills and extremely short on economic resources, and limited social networks risk increased for youth to engage in antisocial behaviors. Risk is 'community wide’.

The Waltham Forest Report was a longitudinal epidemiological study of behavior problems in preschool children. The study was conducted from 1969to 1982. The study purpose was to identify and assess behavior problems. Data was collected using intensive interviews and psychological assessment through behavior screening questionnaire, behavior checklist and assessments of language development (Richman, Stevenson \& Graham, 1982). Findings: 
Parental variables, (i.e. maternal stressors) greatly impact a child’s behavior problems or engagement in antisocial behavior at the pre-school age. The externalizing antisocial behavior observed through aggression at age three, continued to account for $67 \%$ of the child antisocial behavior at age 8. Symptoms remained stable in prevalence at three, four, and eight years of age. Males were more likely than females to remain disturbed.

The Oregon Youth Study, initiated in 1998, was longitudinal study with participants randomly selected from neighborhoods characterized by the tenth highest delinquency rates. The study cohort consisted of two successive birth cohorts of $4^{\text {th }}$ grade boys and their families totaling a sample of 206 participants. Data was collected using multiple method and multi-agent measures: observations, interviews, questionnaires, videotapes of family problem-solving tasks; telephone contacts with parents, and the child's sampled behavior at home. Teacher questionnaires, peer nominations, achievement and intelligence tests sampled school adjustment. These were supplemented with juvenile court records. Children were assessed in the $4^{\text {th }}$ grade. This assessment was combined with police arrests data collected every other year through high school (Patterson, et al., 1998). Findings: Bidirectional relations between parent and child contribute to long term stabilities thus if disrupted the child is much more prone to antisocial behavior. "Parental discipline and monitoring accounted for $30-52 \%$ of variation in latent constructs of antisocial behavior” (Patterson, et al., 1998, p.534). The effects of contextual variables such as social disadvantage and family transitions (divorce, re-parenting) are largely mediated by whether the parenting practices are disrupted. Low income and large family size are direct contributions to chronic antisocial behavior. 
The Philadelphia cohort study was a delinquency birth cohort longitudinal study. It began in 1945 and follow-up data was collected at age twenty-six and thirty years old. The cohort consisted of males born in 1945 that were residents of the city of Philadelphia. They were studied from their $10^{\text {th }}$ to $18^{\text {th }}$ birthdays. The cohort was drawn from $10 \%$ (978) of those that met the study criteria. Data for the study was collected using inferential and descriptive analysis. The researcher searched the files of three school systems (public, private and parochial), the police department of Philadelphia records, and the selective service system for the name of all males born in 1945 (Wolfgang, Thornberry \& Figlio, 1987). Findings: Race and socio-economic status were among the best predictors of frequent arrests. Race is the most significant factor.

The National Youth Survey was a longitudinal epidemiology study of delinquency and drug use among American youth. The study began in 1975 but was completed in1976. The youth studied were from 11 to 17 years old and consisted of 7 birth cohorts (1959-1965). The cohort consisted of a sample of 8,000 households with youth 11-17 years of age in 1976 . This totaled a cohort for study of 1,725. Data was collected using forms of achievement and involvement scales, peer indexes, and interviews (Elliott, Huizinga, \& Ageton, 1985). Findings: Prior delinquency and involvement in delinquent peer groups are the main factors directly affecting both delinquency and drug use. Minimum presence of two or more predictors provide reasonably good estimation of the level of involvement later on.

The Seattle Social Development Project was a prospective longitudinal study of a panel of youth conducted in 1985. The sample was drawn from 18 Seattle public schools serving high crime areas resulting in cohort for study of 808 participants. Data was collected in two waves using standardized instruments issued to students, parents, and teachers (Herrenkohl, et al., 2000). 
Findings: The results indicate that there are factors in each domain that can help to predict antisocial behavior namely the family, school, community, peer, and individual.

A lot of rich information resulted from the evaluation of the longitudinal studies to shape what is currently known about common predictors of youth antisocial behavior. So what are the common factors from the studies?

Results of review

Following the merger of similarly described factors, common themes were created. The themes resulted using three aspects, 1) either the factors in each study used common words, 2) had similar descriptions of the same concept, or 3) there was an obvious relationship pattern (i.e. parent-child) among the factors. The result was eight reoccurring predictors of youth antisocial behavior across all ten longitudinal studies. They included 1) parent-child relationships (functioning, management practices, attitudes toward violence and discipline); 2) neighborhood support and status (impoverished or disadvantaged); 3) uneasy temperament or a troublesome personality (supported by 8 of the 10 studies); 4) socio-economic status (supported by 6 of the 10 studies); 5) involvement with deviant peers; 6) low academic performance in school combined with school failure; 7) family size (4 or more siblings); and 8) parental criminality, emotional or mental disorder (supported by 3 of the 10). The specificity in definition of the themes came from the common factors from the studies. Each of the eight common themes is discussed briefly in light of the studies. 


\section{Common themes}

The common themes from the study are not all inclusive but were consistently found (in various descriptive forms) in each of the studies reviewed. The findings represent similarity only with the studies reviewed in this paper.

The themes were loosely defined using the factors from each study. For instance, parentchild relationships were defined as any relationship between children and their parents/guardians. This relationship related to the parents/guardians functioning ability, management practices, attitudes toward violence and discipline and towards their children. Neighborhood support and status was defined as any community where the child lives, where there is evidence of poverty resulting in youth being impoverished or disadvantaged due to limited resources. A child's uneasy temperament or a troublesome personality was defined as a child's responds to their current surroundings. Socio-economic status was loosely defined as the economic impact of finances on a child, such as a parents' employment or education. Involvement with deviant peers was simply defined as having deviant peers or gang membership. Low academic performance in school was defined as any evidence of school failure such as poor grades. The other two themes were defined as stated, whether there were more than four siblings in the home and whether the parent had a criminal background and/or emotional or mental disorder.

Description of each common predictor with support from the longitudinal studies

Parent-child relationships. The results suggest that eight of the ten studies overwhelmingly viewed parent-child relationships as an important predictor (Elliott, et al., 1985; Herrenkohl, et al., 2000; Patterson, et al., 1998; Richman, et al., 1982; Sheidow, et al., 2001; West \& Farrington, 1973; Werner \& Smith, 2001). However, not all studies gave the same label 
to this predictor. The Kauai study specifically listed parent-child relationships, divorce, separation, single parent home, poor mother attachment, parent-child conflicts, and long absence from primary caregiver in infancy as factors (Werner \& Smith, 2001). While similar variables such as broken homes, temporary separation from parents; neglectful parents, parental marital conflict, parents’ inconsistency with rules; and parents instability with discipline were identified in the Cambridge Study (West \& Farrington, 1973). The Pittsburgh study identified poor family supervision. Parental support and poor family function were common predictors in the Chicago Youth Development Study (Sheidow, et al., 2001). In the Oregon Youth Study (1998) parentchild relationships were also noted as a strong predictor to long-lasting effects of whether a child would engage in prosocial or antisocial behaviors in young adulthood (Patterson, et al., 1998). The authors conjectured that parental discipline and lack of appropriate monitoring of children accounted for almost $30-52 \%$ of the variation in the latent combination of antisocial behaviors. Stability in parental discipline and monitoring is often reliant on contextual variables such as, social disadvantage or family transitions involving divorce or re-parenting (Patterson, et al., 1998). Evidence suggests that bi-directional relations between parent and child disrupted parentchild relationships. Hence, parental discipline, family transitions, and monitoring are important predictors in youth antisocial behavior (Patterson, et al., 1998).

Several important positive and negative factors in the context of parent-child relationships were identified. The Waltham Forest Report (1982) included mental distress in mothers, disharmonious family relations, and quality of marital relationships as important factors in the context of parent-child relationships. In addition, loving parents, getting along with parents; perception of child by parents; participation in activities with parents; and parents’ 
availability to talk with child and family management practices arose in the National Youth Survey (Elliott, et al., 1985). Lastly, the Seattle Development Project identified factors that included poor family management practices, family conflict, and parental attitudes to violence (Herrenkohl, et al., 2000) as aspects of parent-child relationships.

Individual characteristics. In the Kauai prospective longitudinal birth cohort study, Werner and Smith (2001) reported many of the factors that impact antisocial behavior revolve around the individual. These include the "individual's biological make-up (an intact central nervous system and good health), psychological dispositions (cognitive skills, temperament, and self-efficacy), and the sources of emotional support he or she could rely upon at each stage of the life cycle” (Werner \& Smith, 2001, p.172). It is interesting to note that individuals where these categories are compromised very early in their development are often labeled awkward, restless or withdrawn (Werner \& Smith, 2001). Many of these same individuals suffered from learning disabilities and continued to operate below normal in psychological examination and physical development later on in their childhood (Werner \& Smith, 2001).

The Seattle Social Development Project (Herrenkohl, et al., 2000) highlighted similar factors as common predictors of antisocial behavior at age 18. The authors report when individual characteristics such as hyperactivity, attention deficit, and sensory seeking were identified at an early age, the chances of youth engagement in violent antisocial behavior was twice as likely to occur. In addition, negative correlations to social ties in school and community, such as low academic performance, low commitment, low educational aspirations, and multiple school transitions at all ages increased risk. This chain of risk factors, coupled with behavior 
problems displayed at school and with peers seriously increased the antisocial behavior risk (Herrenkohl, et al., 2000).

Neighborhood support and status. The cohort studies show the presence of emotional support (in and outside of the home), the number of stressful life events, and the child's scholastic ability foster the normal development and transitions through the life-course. For example "troubled youths who had grown up in poverty, but who were socially and intellectually competent profited more from naturally occurring opportunities that opened up for them in adulthood” (Werner \& Smith, 2001, p.180). This was also true of the Chicago Youth Development Survey (Sheidow, et al., 2001).

Poor family functioning, in impoverished communities, provides limited social networks of support and concern, increases violent exposure and accumulates risks for antisocial behavior. As a result, in communities plagued with social ills and extremely scarce economic resources, youths are at a higher risk; however, improvement in social networks and processes buffer these effects (Sheidow, et al., 2001).

The Seattle Social Development Project similarly added the following predictors to our findings: peer, family and community, parental attitudes to violence; poor family management practices; parental criminality, and family conflict. When these occurred between the ages of 10 and 14, the risk of engagement in antisocial behavior doubled at age 18 (Herrenkohl, et al., 2000).

Socio-economic status. In the Philadelphia cohort study, where researchers followed a population up to age 30 , some of the risk factors were similar to those described in previous 
studies. The authors reported that non-white and lower socio-economic groups were more likely to graduate from juvenile to adult offenses (Wolfgang, et al., 1987).

Peer \& School. The Kauai study highlighted the fact that negative peer relationships and negative social ties severely impact the development of the child into adolescence and adulthood (Werner \& Smith, 2001). When support systems are lacking or if the existing support system is not utilized, youths are edged into the engagement of antisocial behavior (Werner \& Smith, 2001). For instance, involvement in antisocial behavior almost tripled and quadrupled when an individual had delinquent friends, was involved with a gang; the community was disorganized; drugs were readily available; or knowing adults involved in criminal activity (Herrenkohl, et al., 2000).

Family size. Three of the longitudinal studies found family size as a re-occurring predictor in engagement in youth antisocial behavioral. Although not explored fully in this review, the Rochester Youth Development study reported similar findings of the structural position including the economic position surrounding family employment. This is important for the predictor of family size. A family of 4 or more siblings (West \& Farrington, 1973) may cause undue stress to the family’s position, thereby impacting the child’s trajectory of engagement in youth antisocial behavior (Browning, Thornberry \& Porter, 1999).

Parental criminality, emotional and mental disorder. Farrington and Coid (2003) identified very similar risk factors to those suggested as common predictors. The Cambridge findings highlighted the fact that family, via the parental variables, severely impact the child trajectory to engagement in antisocial behaviors. The findings indicated $63 \%$ of boys with convicted fathers and $61 \%$ of those with convicted mothers were more likely to be considered 
antisocial and to be convicted by age 32. As a result, the authors concluded that antisocial parents tend to have antisocial children (Farrington \& Coid, 2003; West, 1973).

\section{Discussion/ Recommendations}

What is obvious, following the review, is that despite its limitation, longitudinal studies have largely complemented the work of explaining predictors of youth antisocial behavior. It is not that researchers did not know that family (parents, children and siblings), among other predictors, impacted a child’s behavior. It was that studies did not consistently show 'what', within each unit, affected the child, such as the common factors in the family. This paper has attempted to evaluate these ten studies to do just that, in a hope to better inform the work of practitioners to respond to youth antisocial behavior. In doing so, the studies have been able to provide consistent factors, over the youth's life-course, that can be used to interrupt the negative trajectory of various youth antisocial behaviors.

Sadly, the time constraints and possibility of outdated data, which comes with longitudinal studies, have kept researchers at bay from this study design. However, evident from the ten studies, there is a way to make it work - to feed the need for answers in the here and now. For instance researchers can conduct successive cohort studies or samples, collect data annually or sequentially at multiple times, at multi-levels or gather multiwave assessment measures. This could allow for more in-depth comparisons after the completion waves and those that continue to participate in current and future waves, while getting findings out (Sheidow, et al., 2001). In addition researchers can use multi-agent measures involving various tools of observation of home behavior, interviews of parent and child, questionnaires, and even school records, or official data (Patterson, et al., 1998). The goal is to follow persons over the life course, to see 
impact of early decisions, characteristics, and environmental factors on explaining antisocial behavior. However, we need not forsake the quality of these results at the expense of not wanting it to take long.

Conclusions

After centuries of trying to respond to antisocial behavior in the American society it is important to beware of the common predictors. The hope is that recognizing common predictors, early in a child’s development, may interrupt a child's negative behavior trajectory. However, the time restrictions placed on longitudinal studies limits researchers from using this format frequently. What was clear though, from the studies reviewed, was that despite its limitations, various longitudinal studies can be carried out in cycles (where data is collected annually and shared but the study continues). 


\section{References}

Bartlett, H.M. (2003). Working definition of social work practice. Research on Social Work Practice 13(3), 267-270.

Bartollas, C. \& Miller, S. J. (2005). Juvenile justice in America. (4 ${ }^{\text {th }}$ Ed.) New Jersey: Pearson Education.

Barton, W. H. (2004). Bridging juvenile justice and positive youth development. In S.F. Hamilton \& M.A. Hamilton (Eds.) The youth development handbook: Coming of age in American communities, pp. 77-102. Thousand Oaks, CA: Sage.

Bernard, T. J. (1992). The cycle of juvenile justice. New York: Oxford University Press.

Bogenschneider, K. (1996). An ecological risk/protective theory for building prevention programs, policies and community capacity to support youth. Family Relations, 45(2), $127-138$.

Bronfenbrenner, U. (1979). The ecology of human development: Experiments by nature and design. Cambridge, MA: Harvard University Press.

Catalano, R.F., Berglaund, H.L., Ryan, J.A.M., Lonczak, H.S., \& Hawkins, J.D. (1998). Positive youth development in the United States: Research findings on evaluations of positive youth development programs. Social Development Research Group: University of Washington. Retrieved March 16, 2006 from: http://aspe.hhs.gov/hsp/PositiveYouthDev99/index.htm.

Chambers, D. E. (2000). Social policy and social programs: A method for practical public policy analyst. ( ${ }^{\text {rd }}$ Ed). Needham Heights, MA: Allyn \& Bacon. 
Downing, P., Stepney, P., \& Jordan B. (2000). Violent youth crime: Rhetoric, research and the responsibilities of government. Educational Studies, 26(1), 67-82.

Elliott, D. S., Huizinga, D., \& Ageton, S. (1985). Explaining delinquency and drug use. Beverly Hills, CA: Sage.

Farrington, D.P. \& Coid, J.W. (Eds.) (2003). Early prevention of adult antisocial behavior (pp. 265-291). Cambridge, UK: Cambridge University Press.

Farrington, D. P., Loeber, R., Stouthamer-Loeber, M., Van Kammen, W. B., \& Schmidt, L. (1996). Self-reported delinquency and a combined delinquency seriousness scale based on boys, mothers, and teachers: Concurrent and predictive validity for African-Americans and Caucasians. Criminology, 34, 493-517.

Hawkins, J.D. (1996). Delinquency and crime: Current theories. New York: Cambridge University Press.

Herrenkohl, T.I, Maguin, E., Hill, K.G., Hawkins, J.D., Abbott, R.D. \& Catalano, R.F. (2000) Developmental risk factors for youth violence. Journal of Adolescent Health, 26(3), 176186.

Howell, J.C. (2003). Preventing and reducing juvenile delinquency: A comprehensive framework. Thousand Oaks, CA: Sage.

Howell, J.C., Krisberg, B, Hawkins, J.D. \& Wilson, J.J. (Eds.) (1995). Serious, violent, and juvenile offenders: A sourcebook. Thousand Oaks, CA: Sage.

Huizinga, D., Loeber, R. \& Thornberry, T.P. (1994). Urban delinquency and substance abuse: initial findings. Research summary. Juvenile Justice Bulletin. Washington, DC: U. S. Department of Justice, Office of Juvenile Justice and Delinquency Prevention. 
Huizinga, D., Loeber, R., Thornberry, T. P., \& Cothern, L. (2000). Co-occurrence of delinquency and other problem behaviors. Juvenile Justice Bulletin. Washington, DC: U. S. Department of Justice, Office of Juvenile Justice and Delinquency Prevention.

Laub, J.H. \& Sampson, R.J. (1993). Turning points in the life-course: Why change matters to the study of crime. Criminology, 31, 301-325.

Laub, J.H. \& Sampson, R.J. (2001). Understanding desistance from crime. In M. Tonry (Ed.). Crime and justice: A review of research, 28, (pp.1-69). Chicago: University of Chicago Press.

Laub, J.H. \& Sampson, R. J. (2003). Shared beginnings, divergent lives: Delinquent boys to age 70. Cambridge, MA: Harvard University Press

Loeber, R. (1990). Development and risk factors of juvenile antisocial behavior and delinquency. Clinical Psychology Review, 10, 1-41.

Loeber, R. (1996). Developmental continuity, change, and pathways in male juvenile problem behaviors and delinquency. In J.D. Hawkins. (Ed.) Delinquency and crime: Current theories (1-27). New York: Cambridge University Press.

Loeber, R. \& Farrington, D.P. (1998). Serious and violent juvenile offenders: Risk factors and successful interventions. Thousand Oaks, CA: Sage.

Loeber, R. \& Farrington, D.P. (Eds.) (2001). Child delinquents: Development, intervention, and service needs. Thousand Oaks, CA: Sage.

Office of the Surgeon General. (2001). Youth Violence: A Report of the Surgeon General (chapter 4). Retrieved March 22, 2005 from http://www.mentalhealth.org/youthviolence/surgeongeneral/SG_Site/summary.asp 
Olson, D.E. (1997). Illinois juvenile justice: A century of experience. School Safety 20-24.

Patterson, G. R., Forgatch, M.S., Yoerger, K.L. \& Stoolmiller, M. (1998). Variables that initiate and maintain an early-onset trajectory for juvenile offending. Development and Psychopathology, 10, 531-547.

Reid, J. B., \& Eddy, M. J. (1997). The prevention of antisocial behavior: Some considerations in the search for effective interventions. In D.M. Stoff, J. Breiling, \& J.D. Maser (Eds.) (1997). Handbook of antisocial behavior, (pp.343-356). New York: John Wiley \& Sons.

Reiss, A.J. (1986). Why are communities important in understanding crime? In A.J. Reiss \& M. Tonry (Eds.), Communities and Crime (pp. 1-33). Chicago: University of Chicago Press.

Richman, N., Stevenson, L., \& Graham, P.J. (1982). Preschool to school: A behavioral study. London: Academic Press.

Rutter, M., Giller, H. \& Hagell, A. (1998). Antisocial behavior by young people. New York: Cambridge University Press.

Sheidow, A.J., Gorman-Smith, D., Tolan, P.H. \& Henry, D.B. (2001). Family and community characteristics: Risk factors for violence exposure in inner-city youth. Journal of Community Psychology, 29(3), 345-360.

Stoff, D.M. (1997). Antisocial behavior research: An introduction. In D.M. Stoff, J. Breiling, \& J.D. Maser (Eds.). Handbook of antisocial behavior (xiii-xvii). New York: John Wiley \& Sons.

Stoff, D.M., Breiling, J. \& Maser, J.D. (1997). Handbook of antisocial behavior. New York: John Wiley \& Sons, Inc. 
Walker, H., Colvin, G., \& Ramsey, E. (1995). Antisocial behavior in school: Strategies and best practices. Pacific Grove, CA: Brooks/Cole.

Walker, H.M. \& Sprague, J.R. (1999). The path to school failure, delinquency, and violence: Causal factors and some potential solutions, Intervention in School and Clinic, 35(2), 6773.

Werner, E. E., \& Smith, R. S. (2001). Journeys from childhood to midlife: Risk, resilience, and recovery. Ithaca, NY: Cornell University Press.

West, D.J. (1969). Present conduct and future delinquency: First report of the Cambridge study in delinquent development. New York: International Universities Press.

West, D.J. \& Farrington, D.P. (1973). Who becomes delinquent? Second report of the Cambridge study in delinquent development. London: Heinemann Educational Books.

West, D.J., Farrington, D.P., Gundry, G., Knight, B.J. \& Osborn, S.G. (1977). The delinquent way of life: Third report of the Cambridge study in delinquent development. London: Heinemann Educational Books.

White, J. L., Moffitt, T. E., Earls, F., Robins, L. N., \& Silva, P. A. (1990). How early can we tell? Predictors of childhood conduct disorder and adolescent delinquency. Criminology, 29, 507-533.

Wolfgang, M., Thornberry, T. P., \& Figlio, R. M. (1987). From boy to man, from delinquency to crime: Follow up to the Philadelphia birth cohort of 1945. Chicago: University of Chicago Press. 